\title{
Automation of Traditional Exam Invigilation using CCTV and Bio-Metric
}

\author{
MD Jiabul Hoque ${ }^{1}$, Md. Razu Ahmed ${ }^{2}$ \\ Dept. of Computer \& Communication Engineering \\ International Islamic University Chittagong \\ Chittagong, Bangladesh
}

\author{
Md. Jashim Uddin ${ }^{3}$, Muhammad Mostafa Amir Faisal ${ }^{4}$ \\ Dept. of Electronic \& Telecommunication Engineering \\ International Islamic University Chittagong \\ Chittagong, Bangladesh
}

\begin{abstract}
In education, whilst e-learning has been playing a significant role over the last few years due to its flexibility and remote-based education system, majority of courses are still relying upon traditional approaches of learning due to the lack of integrity and security of online based examinations and assessments in e-learning. As such, traditional approach of examination system is considered superior method than eexamination but it has few limitations in its tag such as excessive number of physical resources (invigilators) is required and high occurrences of malpractices by the students during exam. The objective of this paper is to develop a framework for traditional pen and paper based examination system where number of invigilators will substantially be reduced and malpractices by the students during exam will be abolished. In order to implement the proposed examination system, educational institutions are required to preserve a database using Parallax Data Acquisition tool (PLX-DAQ) that incorporates bio-metric information of all students. Before entering in the examination hall, examinees go through authentication process via bio-metric reader that is attached in front of each exam hall. During the examination, examinees are monitored and controlled by an invigilator from distance through the use of 360-degree Closed-Circuit Television (CCTV) cameras as well as ultra-high sensitive microphones and speakers. Here, CCTV cameras are used to monitor examinees physical malpractices and microphones are used to control examinees vocal malpractices. Only one invigilator is required for n-number of exam halls in this process. The communication between students and invigilator can be done with microphones and speakers attached in both exam halls and invigilator room. This model will wipe out malpractices during examination. It will be a cost effective, simple and secure solution of complex traditional exam invigilation process.
\end{abstract}

Keywords-Automation in invigilation; bio-metric authentication; CCTV monitoring; e-assessment; Parallax Data Acquisition Tool (PLX-DAQ); traditional invigilation

\section{INTRODUCTION}

There are two types of examination systems that are followed in Bangladesh such as online examination system and offline or paper based traditional examination system. Online examination system is encountering numerous issues related to integrity, security and ethics. As such, traditional examination system (room based) is still so popular and holding number one choice for assessment [1]. Online examination system is out of the scope of this paper.

Traditional room based examination system has been increasingly popular in any form of educational institutions such as Universities, colleges and Schools, etc. for their student's regular assessment from early nineteenth century. Besides, this type of examination system is the default assessment method for selection during recruitment of numerous organizations [2]. However, requirement of excessive number of resources and hence, the cost incurred, as well as alarming number of malpractices by examinees throughout the process of examination in recent days have made question marks on traditional room based assessment technique. Inaccurate authentication of examinees before sitting for the exam as well as massive malpractices during exam is mainly two areas of traditional exam invigilation system where examinees try to breach the system [1]. Currently, students require providing their ID card and/or admit card to enter the exam hall which is highly insecure in this technological world as anyone can forge those documents and enter the exam hall as a legitimate examinee. Moreover, it is impractical to ask few invigilators to monitor and control an exam hall filled with full of examinees successfully and hence, massive malpractices are exercised by the examinees. Furthermore, the cost associated with traditional exam invigilation system is very high as it requires many invigilators and other form of resources which makes the system unfeasible [3]. In order to abolish shocking malpractices by examinees as well as to reduce cost of existing complex traditional approach of exam invigilation system, bio-metric system of authentication need to be introduced and automated monitoring and controlling of exam hall is needed to be established.

Before making any question on existing exam invigilation system a number of literatures have been reviewed. An automated exam invigilation system using bio-metric and CCTV has been proposed in order to resolve shortcoming of traditional room based exam invigilation system. The proposed model has been implemented using fingerprint sensor module, microcontroller, DC motor, PLX-DAQ, CCTV, speakers and ultrasensitive microphones etc. Bio-metric module of the proposed system will ensure that only registered and legitimate examinees are allowed to enter in the exam hall as well as 360 degree CCTV and ultra-sensitive microphone and speaker system will guarantee that there will be zero malpractices in the exam hall and only one invigilator will ensure it from distance [3]. The proposed model will nullify malpractices currently prevalent due to flaws in exam invigilation system and will reduce substantial amount of cost incurred by the complex traditional exam invigilation system. It has been identified that proposed system will be much cheaper and highly efficient 
alternative of current suggested system proposed by different researchers.

The rest of the paper is prepared after introduction as follows: Section II reviews the related works and finds out the potential gaps about traditional exam invigilation systems. In Section III the proposed exam invigilation model is developed and in Section IV the proposed model is implemented. And finally, Section V focuses on some discussions, conclusions and future improvements.

\section{RELATED WORKS}

Even though online examination system has been emerging, traditional room based examination system is still considered as principal examination method by any types of organization for any forms of written exam such as recruitment, academic examination, and public service examination etc. [4]. Online examination system has severe issues of authentication as well as hacking of exam materials before or during exam [5].

Currently, it is observed that student ID card and/or registration form (which is easily alterable in this digital world) is used for the purpose of authenticating legitimate examinee during examination. Besides, invigilators (two or more) are used to control and monitor the exam hall which is proven costly but is failed to eradicate malpractice by the examinees during exam. Some researchers proposed some innovative exam invigilation model, prototypes or system for traditional exam invigilation [6]. However, majority of them are either impractical to deploy or insecure, or are poorly accepted by users, and overall, failed to abolish malpractices during examination.

E-assessment relies on computers and controlled exam environment where examinees fail to acquire illicit help from environment surrounding the examinees [7]. However, some authors suggested that students can violate the rules and regulations imposed by e-assessment authority [8]. Numerous authors have proposed incorporating a human invigilator during online assessment to hinder suspicious actions of examinees and to promote academic integrity [9]. Conversely, countless difficulties in involving human invigilators during eassessment have been notified by some recent studies. For instance, invigilator allows examinees for malpractices during e-assessment and in return he/she receives some form of benefits from examinees [10]. Besides, invigilator could face difficulties in identifying lookalikes examinees. Those are the few of many reasons unsecure e-assessment has not been deployed by many institutions around the globe [11].

In case of traditional exam based studies, an embedded exam invigilation system was proposed where an improved version of regular traditional exam invigilation was presented. Each student is provided with an electronic ID card as well as an electronic card reader which is serially interfaced with invigilator's computer to authenticate students before entering the exam hall [12]. The system had severe flaws in authentication model as anyone can sit for the exam as long as he holds the electronic ID card. Moreover, the research did not mention about how the exam hall can be monitored and controlled apart from studying authentication part. Similar trend is observed with minor improvement in the following two studies: exam hall invigilation using GSM-GPRS and RFID based exam hall proctoring. In the former one use the location of exam hall for checking authentication as such the whole system would not work if there is a change in the location of exam hall [13]. Later one has some issues as if RFID card stolen or lost then RFID detectors needs to be set up again and this system cannot eliminate impersonation let alone eradicate malpractices during exam [14]. Some researchers suggested an exam hall invigilation system that authenticates examinees based on password [15]. As we all know password can be hacked, tempered or forgotten as such even legitimate examinees are prevented to enter the exam hall and create chaos. As a result the system cannot eliminate impersonation during exam as well.

The authors has proposed a new automated exam invigilation model using CCTV, fingerprint sensor module, ultra-sensitive microphones and speakers in order to overcome the gaps found in the current and previous literatures in the context of exam invigilation. The proposed model offers simple, secure, efficient and cost effective solution of complex traditional exam invigilation process.

\section{Proposed Exam Invigilation Model}

In order to simplify the complex and expensive traditional examination process, an automated exam invigilation model incorporating bio-metric attendance system, 360 degree CCTV, ultra-sensitive microphones and speakers has been proposed. The proposed model of exam invigilation system is depicted in Fig. 1, where following list of acronyms has been used:

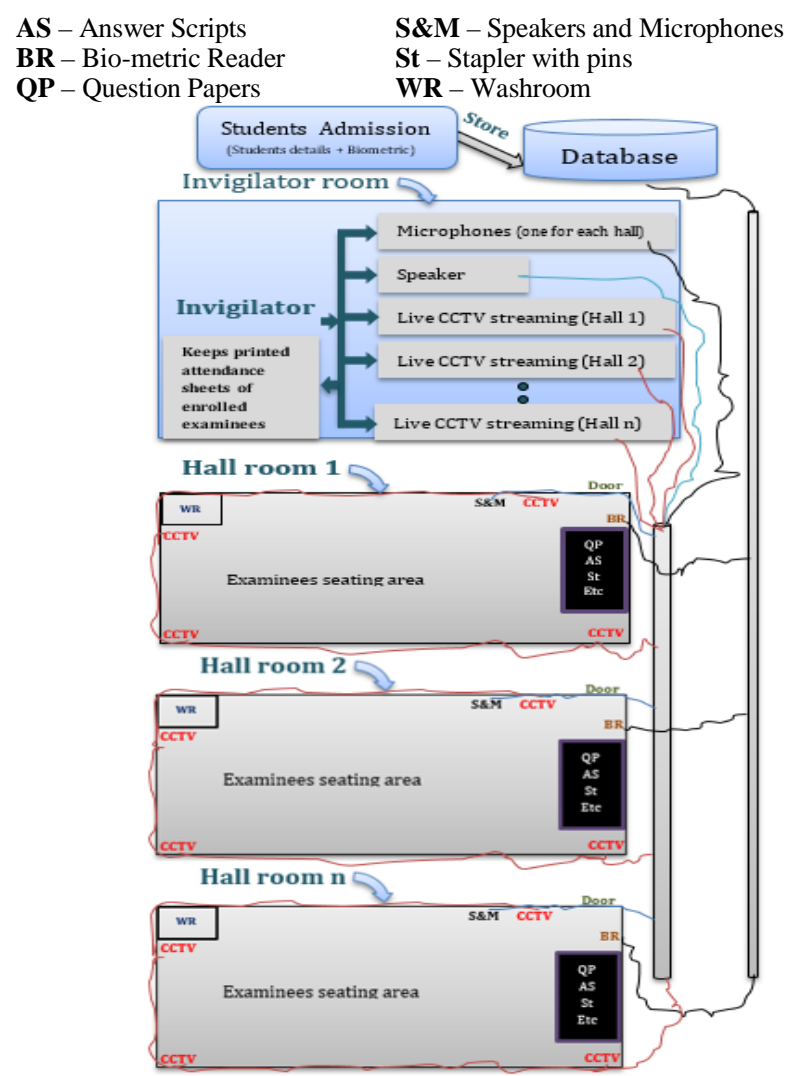

Fig 1. Proposed Exam Invigilation Model. 


\section{A. Working Principle}

Following steps illustrate how the proposed exam invigilation model works:

\section{Phase 1}

Step 1: Students provide their details along with bio-metric (fingerprint [thumb]) during admission to the Institution (University/College/School/institute/coaching centre/etc).

Step 2: Students information together with bio-metric is stored in a database.

\section{Phase 2}

Step 3: Before the examination period, Institutions publish exam routine incorporating courses name, course code, exam date and time, building name, address, floor number, room number, seat number etc. based on students' enrolment of the particular subjects. Students aware about the exam details well before the exam through the notice board as well as respective web sites.

\section{Phase 3}

Step 4: Each exam hall is equipped with fingerprint biometric reader, CCTV, microphones, speakers, wall clock and washroom. Each exam hall is arranged in such a way that the exam hall will have only one door and the invigilator from the invigilation room can control the door remotely.

Step 5: Invigilator together with a helper set up exam halls at least 30 minutes before starting the exam.

- Arrange seat plan

- Provide answer sheets, question papers within sealed envelope, loose papers, stapler with pins, empty envelopes (to keep answer sheets after the exam) etc.

Step 6: Examinees approach to the exam centre 20 minutes before commencing the exam. Examinees make queue just outside the door of respective exam hall assigned to them. Biometric reader is set up next to the door of each exam hall. Each examinee provides bio-metric [for the purpose of authentication] using bio-metric reader in order to enter the exam hall.

- If the bio-metric information provided by the examinee matches with the information stored in the database then door of the exam hall will be automatically open and respective student is allowed to sit for the exam. In addition, a record of each examinee for a particular subject is sent to invigilator.

Step 8: Examinees collect answer script from a designated place within the exam hall as well as start filling up the necessary details in the answer script.

Step 9: Every examinee is instructed by the invigilator from invigilator room through microphone/speaker to collect question paper from the desk two minutes before commencing the exam.

Step 10: If everything goes well and predicted then invigilator provides signal to start writing to examinees of all exam halls.
Step 11: Invigilator room is equipped with a networked computer, a printer, CCTV live streaming display unit, microphone, and speaker. Invigilator keeps a copy of attendance of all examinees that enrolled for the examination on a particular day/time. Invigilator compares total enrolled examinees for a particular course with the actual attendance in the exam (got the list through bio-metric before commencing the exam).

Step 12: Doors of the examination halls are locked after 30 minutes of examination elapsed. If any examine comes after 30 minutes of examination then he/she will not be allowed to sit for that particular exam.

Step 13: During the examination, examinees (one at a time) are allowed to communicate with invigilator using microphone/speaker.

Step 14: Each examinee stop writing when they are instructed to do so by invigilator. After finishing the exam, examinees arrange the answer sheet (staples loose paper, if any) and submit it in a designated place within the exam hall. When all examines submit their paper then they are allowed to leave the exam hall one by one.

Step 15: No examinee is allowed to leave the exam hall within the duration of the exam. In case of unusual circumstances, he/she must discuss the matter with invigilator and get the permission to leave.

Step 16: Invigilator locks the door of exam hall after leaving all examinees. Invigilator along with a helper goes to each exam hall to collect the exam materials.

Step 17: After returning to the invigilation room, invigilator counts all the answer scripts and matches with the attendance sheet.

\section{B. Responsibilities of Invigilator}

Invigilator performs the following tasks before (Invigilator along with an assistant physically visits all exam halls) commencing the exam invigilation:

- Check any unusual stuff (such as writing exam material on wall or on table by students, keeping exam materials inside the washroom, etc.)

- Check to see CCTVs, bio-metric reader, Microphones and Speakers are in right place and in working condition.

- Arrange examinees seating area that identify students (attaching student name and ID on respective table)

- Placing exam materials (answer scripts, loose papers, question papers (sealed), and stapler with sufficient pin, etc.) on the desk.

Invigilator performs the following tasks during (Invigilator is in the invigilation room) examination:

- Watch CCTV Live streaming of each exam hall and communicate with examinees through microphone/speaker if required. 
Invigilator performs the following tasks after elapsing particular examination:

- Perform step 16 and 17 mentioned above.

- Sealed answer scripts along with attendance sheet is sent to administration office that is responsible to send answer scripts to respective examiner for marking.

\section{Block Diagram of Proposed Model}

Fig. 2 depicts the block diagram of proposed exam invigilation model:

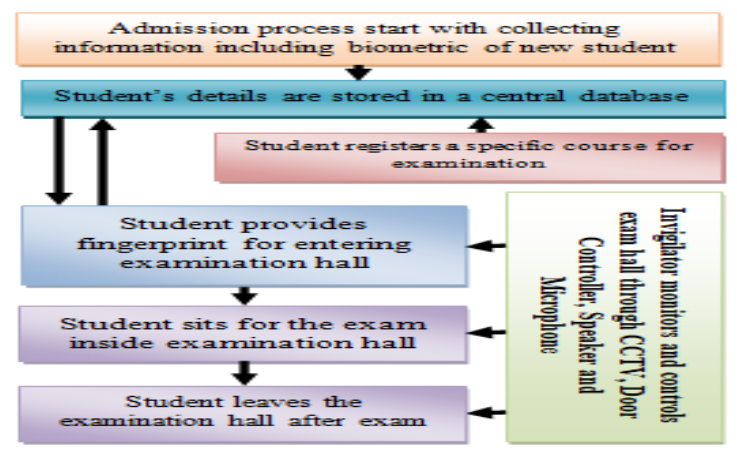

Fig 2. Block Diagram of Proposed Exam Invigilation Model.

\section{Flowchart of Proposed Model}

Fig. 3 illustrates the flowchart of proposed exam invigilation model:

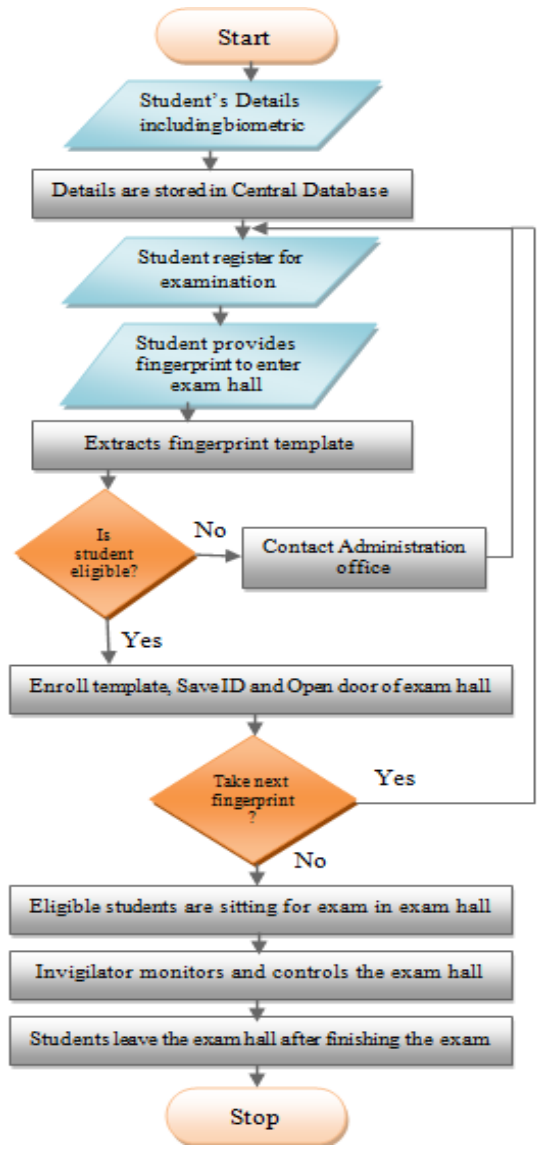

Fig 3. Flowchart of Proposed Exam Invigilation Model.

\section{SYSTEM IMPLEMENTATION}

In this section, hardware and software that are required for implementing proposed system have been described as well as how these materials incorporated to make a prototype of the proposed system has been illustrated.

\section{A. Hardware Description}

In this paper, the hardware comprise of fingerprint module, microcontroller, CCTV, microphone, Speaker, LED, motor driver, DC motor, door, diodes, capacitors and resistors. Among them following notable devices have been described:

a) Fingerprint Sensor Module: There are numerous fingerprint modules available in the market such as capacitive, ultrasonic, piezoresistive, piezoelectric, thermal, RF and optical etc. In this paper, an optical fingerprint sensor module (FPM10A) has been used because of its tremendous performance with low cost and low power consumption. The module reads the fingerprint pattern of the examinee and scans the images optically. Besides, it converts the scanned image to digital template and saves the output into the memory [16]. Fig. 4 shows optical fingerprint sensor module (FPM10A):

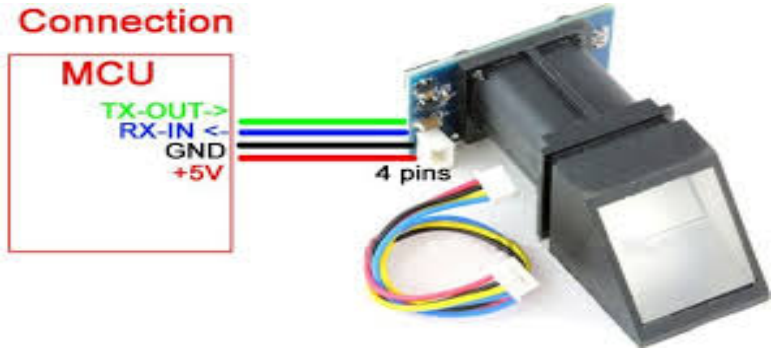

Fig 4. Optical Fingerprint Module.

b) Arduino Uno with ATmega328P Microcontroller: In this paper, Arduino Uno microcontroller board with ATmega328P microcontroller has been used:

- To connect with fingerprint module to get fingerprint template of examinee and compare it with stored fingerprint of corresponding examinee. If the fingerprint matches then the information of the examinee is stored in excel database.

- To give signals to the DC motor (attached with the door) via motor driver.

Fig. 5 illustrates Arduino Uno board with ATmega328P microcontroller [16]:

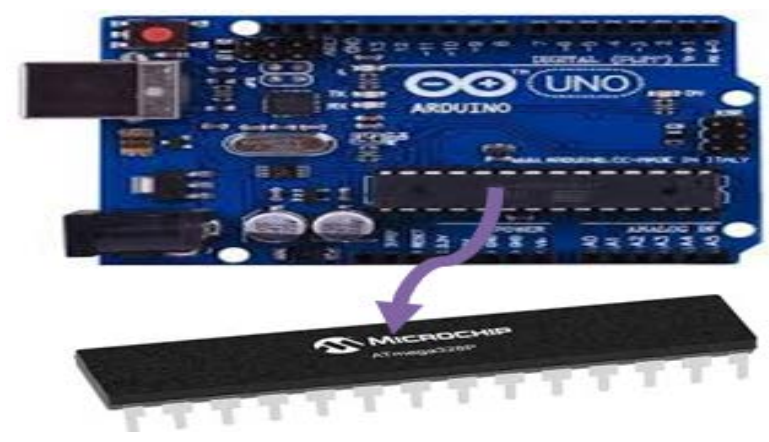

Fig 5. Arduino Uno with ATmega328P Microcontroller. 
c) Driver for Motor: This is a driver for motor which can be used as a bridge between microcontroller and motor. It receives input signals from microcontroller and produces output signals for corresponding motor. Here, L293D IC has been used as a motor driver IC. It is a dual H bridge IC where one bridge is capable of driving a DC motor in bidirectional way [16]. Fig. 6 depicts the IC L293D of a motor driver:

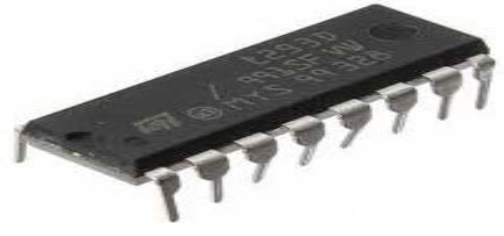

Fig 6. Motor Driver IC.

d) Motor (DC): Fig. 7 demonstrates a small DC motor that runs with very low voltage starting from 0.5 volts. The motor is attached with the door in order to control it. The control signal comes from the microcontroller via motor driver [16].

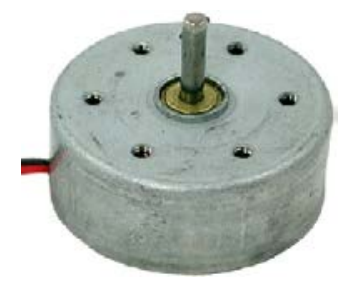

Fig 7. Small DC Motor.

e) Door: In real scenario, a door will be used to enter the examinees in the exam hall after authenticating by the biometric system. However, in this implementation a small board has been used to replicate the real scenario.

f) CCTV:In this paper, a 360 degree CCTV camera has been used in order for invigilator to view entire exam hall at once [16]. Fig. 8 shows the CCTV camera:

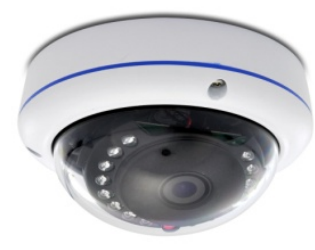

Fig 8. CCTV Camera with 360 Degree View.

a) Microphone \& Speaker: In order to ensure examinees in the exam hall are not taking each other a MS-MMM-1 ultra sensitive microphone has been used in this paper [17]. Fig. 9 depicts a MS-MMM-1 ultra sensitive microphone.

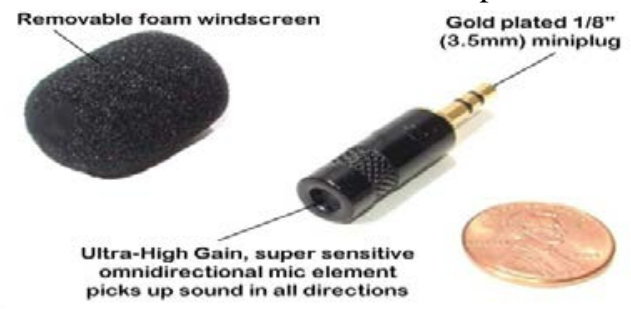

Fig 9. MS-MMM-1 Ultra-Sensitive Microphone. b) LCD: A 16x4 LCD display with 12C interfaces has been used in this paper in order to display necessary information required for examinees to provide their fingerprint [17]. Fig. 10 shows a 16x4 LCD display unit.

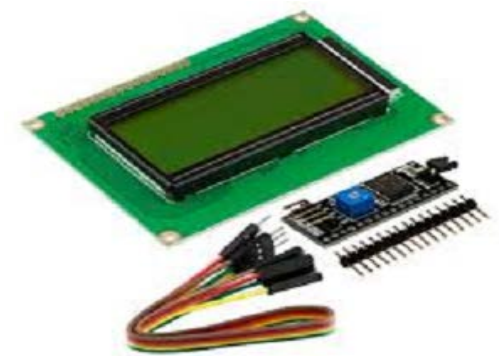

Fig 10. A 16x4 LCD Display.

\section{B. Software Description}

The following software materials have been used to implement the proposed exam hall invigilation model:

\section{a) PLX-DAQ \& Microsoft Excel}

PLX-DAQ stands for parallax microcontroller Data Acquisition which is used as add-in for Microsoft Excel. It is a software tool that is capable of recording up to 26 channels of data from sensors via microcontroller and plots those data in real time using Microsoft Excel. Moreover, rigorous analysis of collected data through sensors and monitors the equipments in real time easily possible by the use of PLX-DAQ [18].

As PLX-DAQ is an add-in of Microsoft Excel, PLX-DAQ run together with Microsoft Excel. PLX-DAQ needs to setup in order to acquire data from microcontroller. It supports any communication port from 1 to 15 and baud rate up to $128 \mathrm{k}$. Here, com port 7 and baud rate 128000bps have been configured. Fig. 11 illustrates PLX-DAQ data acquisition for Excel:

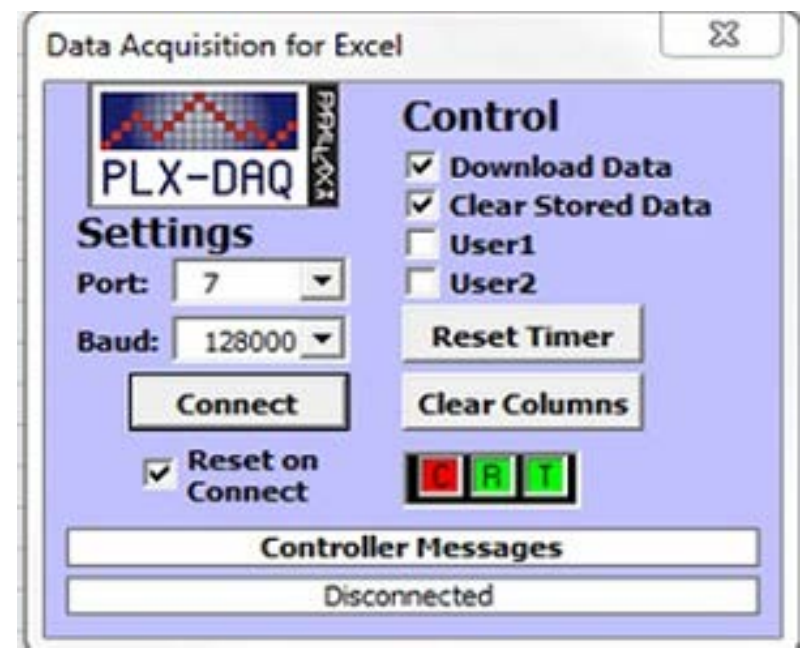

Fig 11. PLX-DAQ Setup for Data Acquisition.

\section{Implementation}

Fig. 12 illustrates how information is passing from one device to another in order to accomplish automated exam invigilation process. 


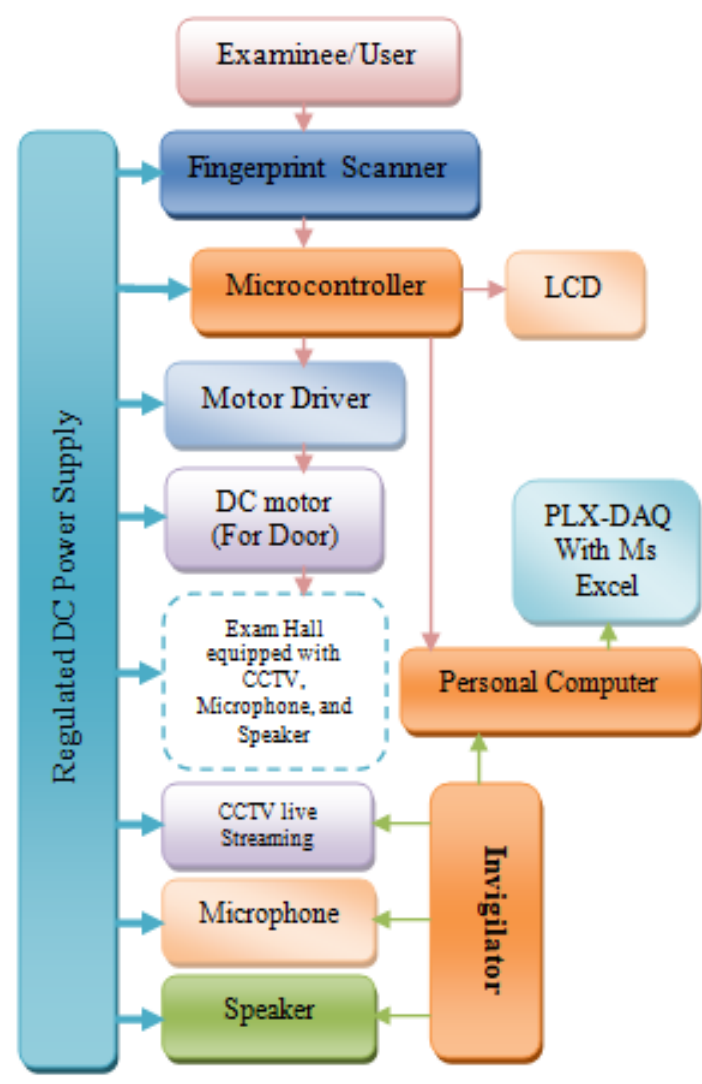

Fig 12. Information Flow Diagram of Exam Invigilation System.

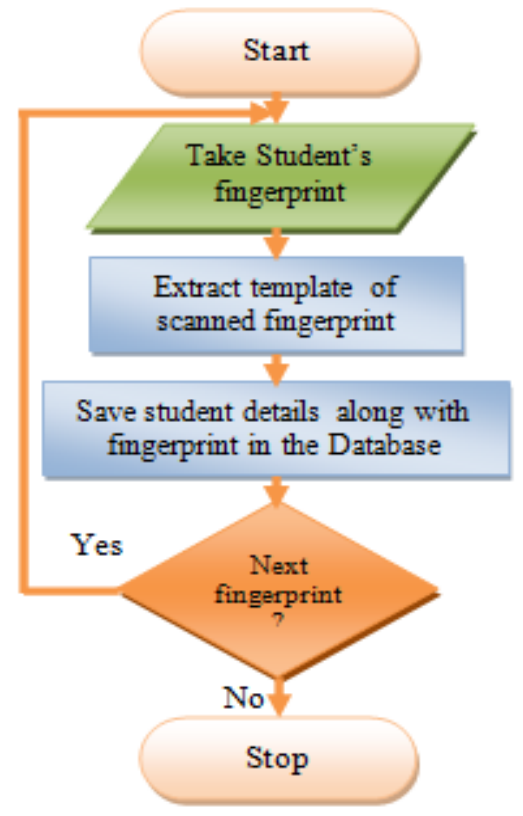

Fig 13. Flow Chart of Bio-Metric System during Admission.

It can be seen from the above figure that majority of the devices require uninterrupted and regulated DC power supply in order to run the examination process smoothly. Different devices require dissimilar level of voltage level as such regulated DC power supply provides power according to the device's power requirements [18].

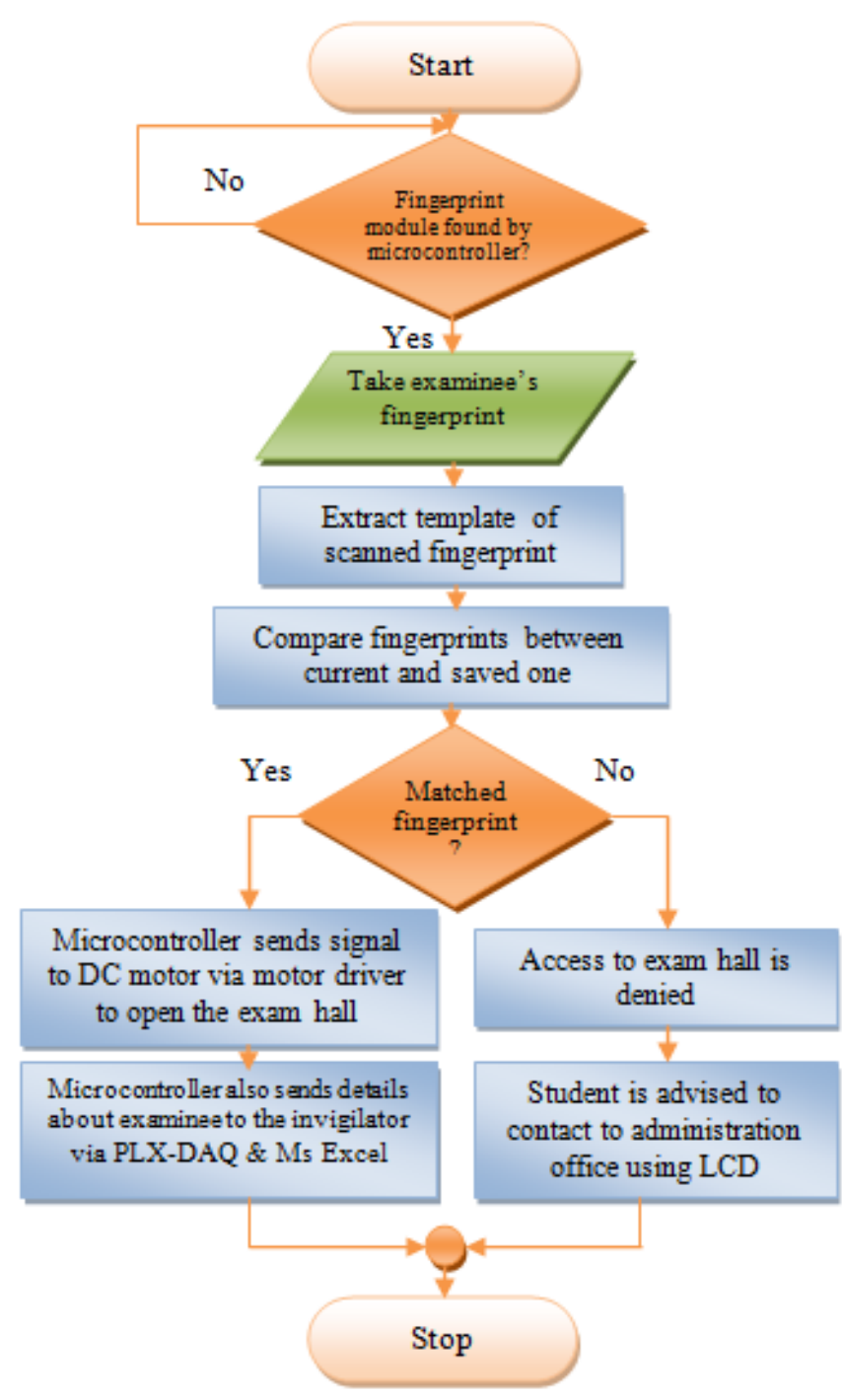

Fig 14. Flow Chart of Bio-Metric System during Exam Hall Entrance.

The exam invigilation system has fingerprint sensor scanner connected with microprocessor. The LCD display unit which is also connected with microprocessor assist user by displaying the activities of enrolment and authentication. Fig. 13 and Fig. 14 illustrate activities of bio-metric system during student's admission and during examination hall entrance for sitting examination respectively.

As long as the system is powered on, the fingerprint sensor offers user to place their finger to be scanned. Fig. 15 depicts the information which is offered to user initially.

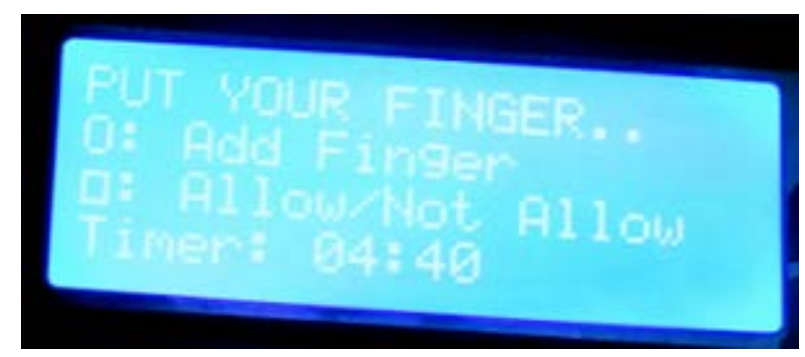

Fig 15. Welcome Message to the User. 


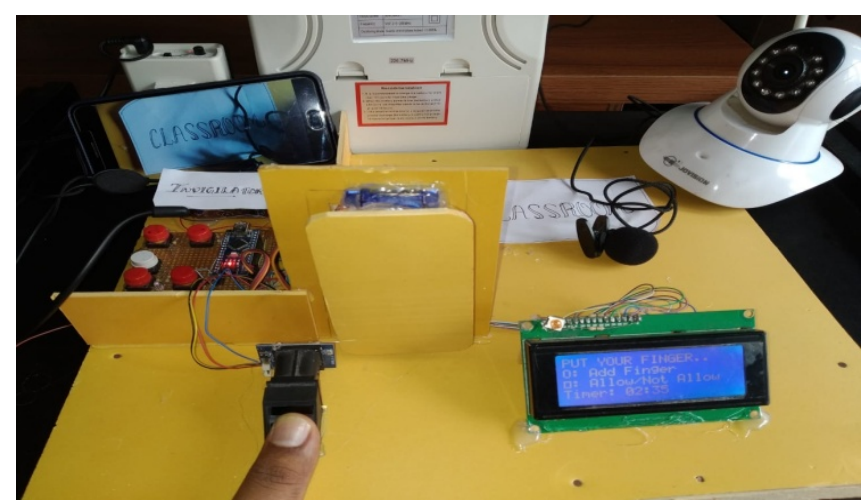

Fig 16. Examinee Puts their Fingerprint for Authentication.

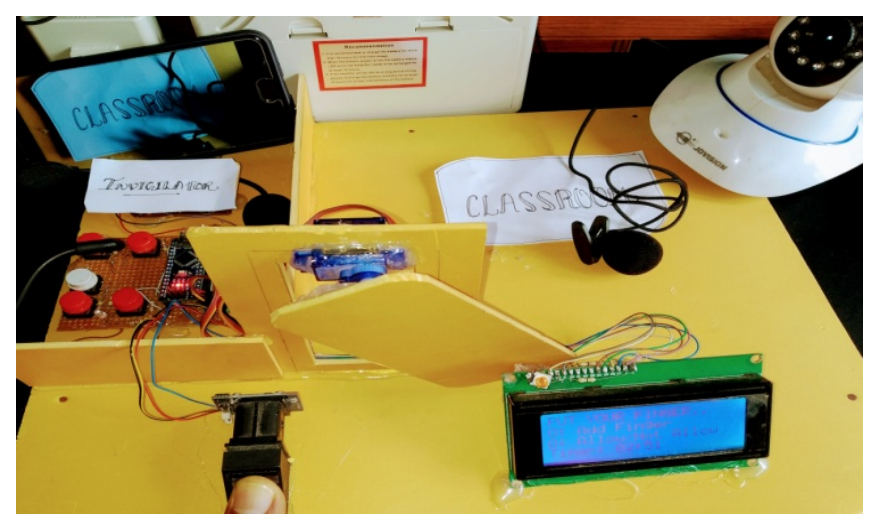

Fig 17. Opening Door Shows Successful Authentication.

User puts the finger on fingerprint sensor scanner in order to scan their fingerprint for authentication. Fingerprint module converts the scanned image to corresponding digital template. Now, microcontroller compares the current template of the scanned image with the stored one in the database scanned during exam registration. If there is a match between two then microcontroller send a signal to the DC motor via motor driver to open the door of exam hall. However, if there is no match between the fingerprint templates then the system inform user that "Access is denied" and contact to administration office as soon as possible to resolve the situation. Therefore, the system hinders unauthorized access of exam of from counterfeit users.

TABLE I. BIO-METRIC ATTENDANCE OF EXAMINEES

\begin{tabular}{|c|c|c|c|c|c|}
\hline \multirow{2}{*}{ SL No } & \multicolumn{5}{|c|}{ Bio-Metric Attendance of Examinees } \\
\hline & Student ID & $\begin{array}{l}\text { Due } \\
\text { Entry }\end{array}$ & $\begin{array}{l}\text { Late } \\
\text { Entry }\end{array}$ & Time & Date \\
\hline 1. 1 & ET-1504 & YES & NO & 9.35AM & $7 / 26 / 2019$ \\
\hline 2. & ET-1504 & YES & NO & 9.37AM & $7 / 26 / 2019$ \\
\hline 3. & ET-1504 & YES & NO & $9.48 \mathrm{AM}$ & $7 / 26 / 2019$ \\
\hline 4. & ET-1504 & YES & NO & $9.55 \mathrm{AM}$ & $7 / 26 / 2019$ \\
\hline 5. & ET-1504 & NO & YES & 10.03AM & $7 / 26 / 2019$ \\
\hline 6. & ET-1504 & NO & YES & 10.05AM & $7 / 26 / 2019$ \\
\hline 7. & ET-1504 & NO & YES & 10.10AM & $7 / 26 / 2019$ \\
\hline
\end{tabular}

The following figures show the actual implementation of the proposed automated exam invigilation model where door of the exam hall is remained shut. Fig. 16 depicts authentication of examinee for exam hall entrance whereas Fig. 17 shows opening door after eligible examinee's successful authentication.

Microcontroller sends the information of entire examinees who are sitting in the examination hall after successful authentication to the Invigilator's personal computer through PLX-DAQ as Microsoft Excel document. An invigilator carefully invigilates using 360 degree CCTV as well as controls and monitors the exam hall using ultra-sensitive microphones and speakers.

Table I portrays bio-metric attendance of legitimate examinees before entering the examination hall. Invigilator collects a list of examinees who registered for examination from controller of examination (CoE) division well before commencing the exam. When examinees enter the examination hall after authenticating through fingerprint sensor module, a real time report as an Ms Excel document is sent to Invigilator's computer. Subsequently, Invigilator compares the real time list of examinees with the one already printed from $\mathrm{CoE}$ and takes the action about the examinees that are late or absent after the examination.

\section{CONCLUSIONS AND FUTURE WORKS}

In this paper, automation of traditional exam invigilation model has been implemented using fingerprint sensor module, 360 degree camera, ultra-sensitive microphone and speaker. The model employs a fingerprint sensor module which permits only registered students who enrolled for the examination for a particular course. In this way, proxy (unauthorized student sit for the exam on behalf of registered examinee) in examination which is very familiar in Bangladesh as there are no systems in place to trace them, will be abolished. Hence, students will be motivated to study hard as they know there will be no one to sit for the exam instead of them. Besides, invigilator monitors the exam halls through CCTV live streaming and controls by using ultra-sensitive microphones and speakers that ensures zero malpractice occurrences during exam. Examinees know and fear that there will be someone watching them from distance all the time and they will get expelled for any wrong doing. Moreover, it saves time, money and resources as only one invigilator is required for total examination process. Furthermore, it simplifies the overall exam management process by automating and digitalizing the complex traditional exam invigilation process. The proposed exam invigilation model can be set up in any form of educational institutions (i.e. Universities, Colleges, Schools, and private or govt. institutions etc.) for any type of assessment (i.e. regular exam, admission test, and recruitment test, etc.) not only in Bangladesh but also anywhere in the globe.

This paper is a preliminary part of the full scale research on automation of exam invigilation system incorporating Internet of Things (IoT), Cloud computing and Image processing which will fully automates the traditional exam invigilation system that will simplify the current traditional exam invigilation system with negligible human intervention. Over the coming 
years, every work relating to this domain will be made public in future research papers.

\section{REFERENCES}

[1] M. A. Amin and J. Greenwood, "The examination system in Bangladesh and its impact: on curriculum, students, teachers and society," Springer: Language Testing in Asia, vol.8, issue. 4, 2018.

[2] S. G. Anuradha and B. Kavya, "Automated face detection \& recognition for detecting impersonation of candidate in examination system," International Journal of Scientific \& Engineering Research, vol. 7, pp. 159 - 160, 2016.

[3] S. Soma and S. A. Vidyashree, "An Automated Fraud Detection of Hall Ticket in an Offline Examination System using ANN Classifier," International Journal of Computer Applications, vol. 126, pp. 7 - 12, 2015.

[4] M. P. Nerkar, “Online exam proctoring system," International Journal of Advance Engineering and Research Development, vol. 3, pp. 110 - 118, 2017.

[5] C. J. Case and D. L. King, "E-cheating: incidence and treands among college students," Issues in Information Systems, vol. 15, 2014.

[6] J. Roth, X. Liu, and A. Ross, "Investigating the discriminative power of keystroke sound," IEEE Transection of Information Forensic Security, vol. 10, pp. 333 - 345, 2015.

[7] M. Hoque, M. Ahmed, and S. Hannan, "An Automated Greenhouse Monitoring and Controlling System using Sensors and Solar Power", EJERS, vol. 5, no. 4, pp. 510-515, Apr. 2020.

[8] A. Wahid, Y. Sengoku, and M. Mambo, "Toward constructing a secure online examination system," International Conference on Ubiquitous Information Management and Communication, ACM, pp. 95 - 102, 2015.
[9] M. Ahmed, M. Rahman, and M. Hoque, "Smart Home: An Empirical Analysis of Communication Technological Challenges", EJERS, vol. 5, no. 5, pp. 571-575, May 2020.

[10] J. Chen and X. Liu, "Transfer learning with one class data," Pattern Recognition Letters, vol. 37, pp. 32 - 40, 2014.

[11] Z. U. Ahmed, M. G. Mortuza, M. J. Uddin, M. H. Kabir, M. Mahiuddin and M. J. Hoque, "Internet of Things Based Patient Health Monitoring System Using Wearable Biomedical Device," International Conference on Innovation in Engineering and Technology (ICIET), Dhaka, Bangladesh, 2018, pp. 1-5, doi: 10.1109/CIET.2018.8660846.

[12] P. Shenbagam and R. Kumar, "Exam hall invigilation using CCTV," International Journal of Computer Science and Engineering, special issue, pp. 64 -68, March 2017.

[13] Hoque, M., Kabir, S. and Hossain, K. (2018); Electricity Crisis of Bangladesh and A New Low Cost Electricity Production System to Overcome this Crisis; International Journal of Scientific and Research Publications (IJSRP) 8(7) (ISSN: 2250-3153), DOI: http://dx.doi.org/10.29322/IJSRP.8.7.2018.p7933.

[14] C. Saraswat and C. K. Amit, "An efficient automatic attendance system using fingerprint," International Journal on Computer Science and Engineering, vol. 2, pp. 264 - 269, 2017.

[15] O.O Shoewu, M. Olaniyi, and A. Lawson, "Embedded computer based attendance management system," Journal of IEEE Nigeria Computer Section, vol. 4, pp. 27 - 36, 2018.

[16] M. A. Mazidi, J. G. Mazidi and R. D. McKinlay, The 8051 Microcontroller: A systemetic approach, Pearson, 2012.

[17] S. Pankanti, and S. Prabhakar, "On the Individuality of Fingerprints," IEEE Transaction on Pattern Analysis and Machine Intelligence, vol. 24, 2012.

[18] M. Habaebi and Q. Ashraf, "Autonomic schemes for threat mitigation in Internet of Things," Elsevier Journal of Network and Computer Applications (EJNCA), vol. 49, pp. 112 - 127, 2015. 